\title{
Applied conservation management of a threatened forest dependent frog, Heleioporus australiacus
}

\author{
T. D. Penman ${ }^{1,2, *}$, F. L. Lemckert ${ }^{1,2}$, M. J. Mahony ${ }^{1}$ \\ ${ }^{1}$ School of Environmental and Life Sciences, University of Newcastle, New South Wales 2308, Australia \\ ${ }^{2}$ Research and Development Division, Forests New South Wales, P.O Box 100 Beecroft, New South Wales 2119, Australia
}

\begin{abstract}
Threatened species management should be based on reliable scientific research. The giant burrowing frog Heleioporus australiacus is a threatened species in south-eastern Australia, and is often recorded on land managed for commercial forestry. As a result, management prescriptions have been developed in the absence of significant research data. Here, we review the available research data and assess the potential for forest management practices to impact upon this species. The species is restricted to naturally vegetated areas, but avoids steep areas, large rivers and forests with high levels of vegetative ground cover. Individuals spend the majority of the year in the nonbreeding habitat considerable distances from bodies of water in small ( 0.05 ha) activity areas. Fire is unlikely to have any significant direct effects upon populations of this species, although longer term vegetative changes associated with certain fire regimes may have an impact. Logging is more likely to have a significant short-term effect on individuals in the logging area, but it is not clear whether the species populations are affected in the medium to long term. Current conservation management prescriptions are ineffective for the species and only enforced if individuals are detected. Detection of this species is difficult and relies on strict climatic conditions. Therefore, new prescriptions, independent of detection, are required to provide a landscape approach to the management of this species. We propose that key populations be identified and protection zones established around these populations, which should be geographically separated to provide longer-term protection against stochastic events.
\end{abstract}

KEY WORDS: Amphibian · Management $\cdot$ Forestry $\cdot$ Disturbance impacts

\section{INTRODUCTION}

Ideally, the management of threatened species would always be based on reliable scientific research. In reality, the rarity of many of these species often restricts opportunities for the collection and analysis of threatened species data. As a consequence, the management of these species is based on either the precautionary principle or the 'best guess' approach. Where threatened species research does occur, we have a responsibility not only to present our research within the scientific community, but also to interpret our data in terms of the conservation management of the species. Until recently, the giant burrowing frog Heleioporus australiacus has been an example of a species that has required management with little guidance from research data.

Heleioporus australiacus is a large threatened myobatrachid frog in south-eastern Australia. Records of the species are from the coast and adjacent ranges from Singleton to approximately $100 \mathrm{~km}$ east of Melbourne (Martin 1997, Gillespie \& Hines 1999) (Fig. 1). A disjunction of $100 \mathrm{~km}$ occurs in the records of the species from south of Jervis Bay to Narooma (Lemckert et al. 1998). It has been argued that populations to the north and south of this disjunction represent separate species (Penman et al. 2004, 2005a) but this remains to be confirmed. For the purposes of this paper, we refer only to the northern and southern populations (Fig. 1). 


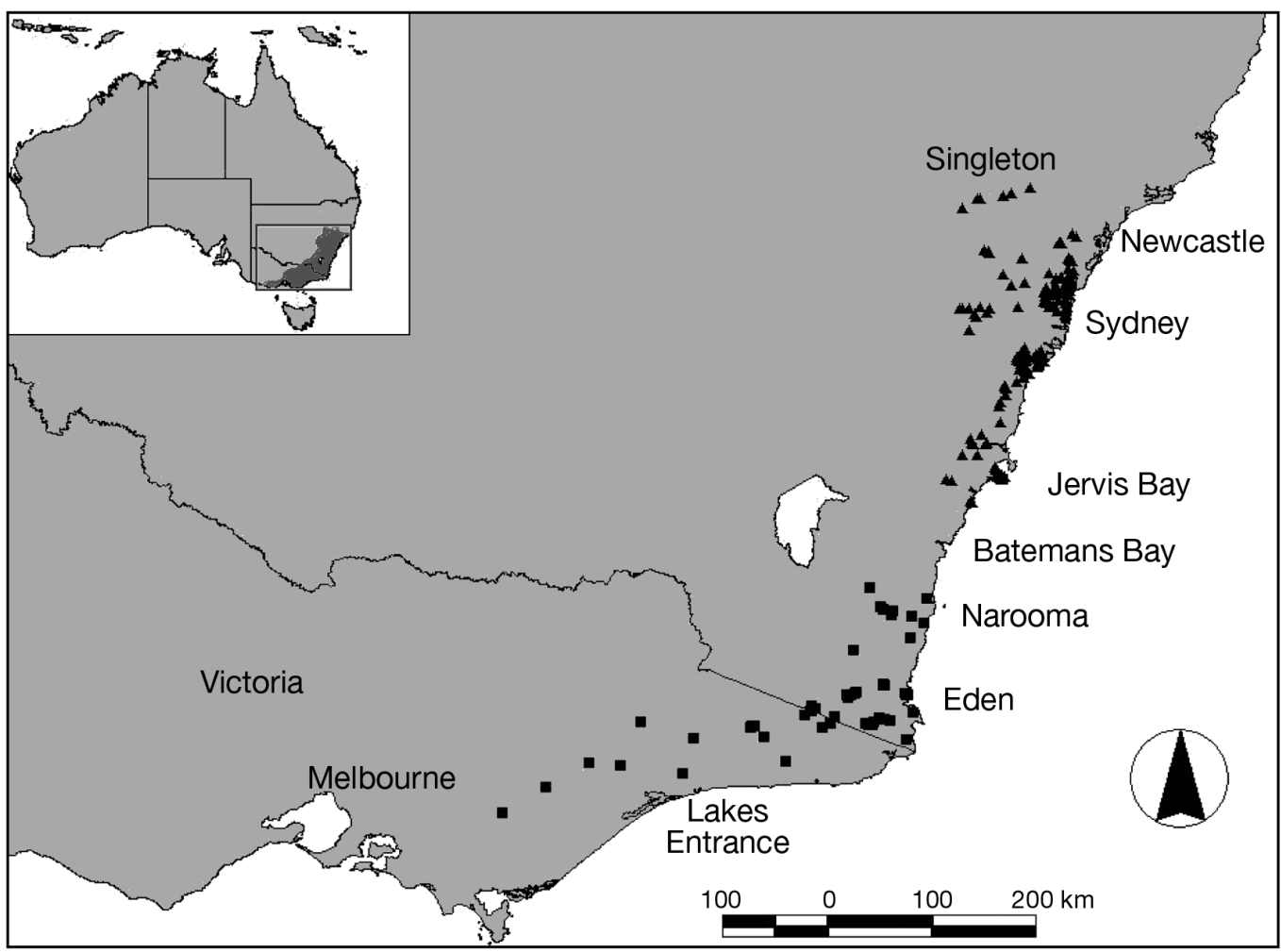

Fig. 1. Known localities of the giant burrowing frog Heleioporus australiacus; $\mathbf{\Delta}$ : northern population sites; $\mathbf{\square}$ : southern population sites. Dark shaded area in inset: study area in New South Wales and Victoria

Throughout its range the giant burrowing frog is considered rare, or at least rarely encountered. As a result the species has been listed under threatened species legislation nationally under the Environmental Protection and Biodiversity Conservation Act 1999, in New South Wales (NSW) under the Threatened Species Conservation Act (TSCA) 1995 and in Victoria under the Flora and Fauna Guarantee Act 1988. Inclusion of this species in threatened species legislation has occurred primarily due to a small number of records of the species suggesting the species occurs in low abundance (Mazzer 1994) and to a poor understanding of the species ecology (Tyler 1997, Penman et al. 2004). The species was listed under the TSCA because its population and distribution were suspected to have been reduced; it was thought that the species faced moderate threatening processes and it was considered to be an ecological specialist (i.e. it depends on particular types of diet or habitat) (Lunney et al. 2000). The 2 main perceived threats to the long-term survival of this species are fire and commercial forestry (Penman et al. 2004).

Management prescriptions have been developed for this species on land subject to commercial forestry, although the prescriptions vary between management regions. In the northern populations (Forests NSWHunter Region), stream buffer zones of $30 \mathrm{~m}$ are established around all drainage lines within $200 \mathrm{~m}$ of a known locality for the species. Two Forests NSW management regions, South East Region and the South Coast Region, cover the southern NSW populations. In the South East Region, if an individual is found, a 200 ha exclusion zone is established, within which no logging is to occur, and there are restrictions placed on conducting prescribed burns. In the South Coast Region, an exclusion zone with a $500 \mathrm{~m}$ radius (78 ha) around the record is established. The more precautionary approach was adopted in these regions, as fewer records exist in these areas compared with the northern populations. In Victoria, where individuals are detected in first order streams or away from streams, a 50 ha exclusion zone is established. For records on second order or higher streams, a linear buffer of $100 \mathrm{~m}$ is established around the stream for $1 \mathrm{~km}$ up- and downstream of the record.

These prescriptions were developed in the absence of significant research data and it is not clear how effective they are. Here, we review the biology of the giant borrowing frog, evaluate its conservation status and assess the potential for logging and fire to impact 
upon populations of this species. Using this information, we assess the appropriateness of existing management prescriptions and propose alternatives that could be applied throughout the range of the giant burrowing frog.

\section{SPECIES BIOLOGY}

A complete review of the species biology is presented by Penman et al. (2004). It was found that little is known of the species' habitat use and behaviour throughout its range. Descriptions of habitat were based on a small number of observations of the species in a relatively small area (e.g. Gillespie 1990, Daly 1996, Lemckert et al. 1998). Northern populations were commonly associated with heath communities (Mahony 1993), whereas the southern populations were reported from a range of forest environments (Littlejohn \& Martin 1967, Webb 1987, Gillespie 1990, Lemckert et al. 1998).

More recent radio-tracking studies have allowed for a comprehensive analysis of the species' behaviour (Lemckert \& Brassil 2003, Penman 2005). These studies have found that individuals spend the majority of the year (>95\%) in forest areas away from the breeding site. In the non-breeding environment, individual frogs have non-breeding territories, which are on average $500 \mathrm{~m}^{2}$ or 0.05 ha. There is no significant difference in the size of the male and female territories; however, male territories are more commonly found closer to the breeding site than female ones (males: mean $=99 \mathrm{~m}$, females: mean $=143 \mathrm{~m}$; Penman 2005). Within each territory an individual will have a number of 'home burrows' or sites they frequently use and a number of single use burrows. Frogs appear to select burrow sites based on the degree of shading from the shrub and understorey layer; however, there were no recorded differences between home burrows and single use burrows. The frogs burrow to depths ranging from 1 to $30 \mathrm{~cm}$, with an average depth of $10 \mathrm{~cm}$.

Traditional habitat modelling approaches have been combined with spatial modelling techniques to assess the habitat requirements of the species, particularly for the southern populations (Penman et al. 2005b, 2007a). In these areas, the species appears to select dry forest environments with low levels of vegetative ground cover. The species is most commonly associated with catchments of first and second order streams (as defined by Strahler 1952), where breeding occurs. Spatial modelling predicted that the species will not occur in steep areas, either because these areas do not have a suitable soil profile for the species to burrow into, or because they do not provide appropriate breeding habitats for the species. Climatic conditions appear inappropriate for the species in large river valleys, coastal lowlands and on high peaks (Penman et al. 2005a).

Studies on this species have been limited by the small number of known sites and the lack of true or known absence sites. As a result, statistical analysis and verification of the derived statistical models is difficult. The lack of true or known absence sites means that any presence/absence statistical approaches require the use of random or null sites. These sites may in fact be occupied by the species, i.e. false negatives, and the inclusion in a model as a negative site will bias model results. This has occurred, as the species is difficult to detect even in areas where it is known to exist. While statistical methods are available for dealing with imperfect detection (e.g. MacKenzie et al. 2003, Tyre et al. 2003, Wintle et al. 2004), data for such models have not been collected for this species.

Detection rates for this species using common amphibian survey techniques are extremely low. This occurs in part because the behaviour of this species is strongly associated with specific environmental conditions. The species is most active following rainfall of at least $5 \mathrm{~mm}$, when temperatures are above $8^{\circ} \mathrm{C}$, humidity above $60 \%$ and in still or light wind conditions (Penman et al. 2006a). Using pitfall traps in known population areas has resulted in detection rates ranging from 1 in 800 trap nights (Penman 2005) up to 1 in 3000 trap nights (Kavanagh \& Webb 1998). Gillespie (1990) reported capturing no frogs in 5400 pitfall trap nights in suitable habitat for the species in eastern Victoria. The rate of detection using nocturnal road transects varies widely according to a number of factors, including habitat traversed, experience of the observer and vehicle speed. Nocturnal road transects are one of the main techniques utilized in pre-logging surveys for this species; however, few have actually detected them. In approximately 250 nights of targeted surveys only 11 frogs have been detected, 10 of which were in one area on one night (C. Slade, A. Fawcett, K. Rowley, Regional Ecologists, Forests NSW, pers. comm.). Auditory surveys are another commonly used technique for amphibian surveys, but these are ineffective for the giant burrowing frog (Penman et al. 2006b).

It is clear that techniques to improve the rates of detection for this species need to be developed. There should be a trial usage of tadpole surveys as an alternative means of detection. This technique is likely to be successful, as the species have large, conspicuous tadpoles (Anstis 2002), which persist in the water bodies for a number of months following hatching (Daly 1996). Tadpole surveys can therefore be conducted for up to 12 mo after a breeding event, independently of climatic conditions. This technique does require that a 
successful breeding event has occurred in an area and may, therefore, not be reliable if an area is only surveyed in a single season.

\section{CONSERVATION STATUS}

It is difficult, if not impossible, to determine the true conservation status of the species. The species may be far more widespread than our current records indicate, as suitable habitat appears widespread throughout the species range. Alternatively, the species may be extremely patchy in its distribution with current records reflecting the main populations in its distribution. Such a distributional pattern may have resulted from natural and anthropogenic disturbances throughout the species' history. If we take this approach, the species may not be difficult to detect - it may simply not be present in the majority of areas surveyed. Management needs to consider both these scenarios.

The majority of the northern populations are located within existing conservation reserves, whereas the southern populations are largely known from land managed for commercial forestry. This result is probably due to the higher level of survey effort in conservation reserves in the northern populations and the much higher density of conservation reserves around the Sydney area. A summary of the reserves and forest land areas where the species has been recorded is presented in Table 1.

Throughout the species distribution there are few areas where more than 5 individuals have been detected. As a result, it is difficult to assess whether populations of this species are remaining stable, declining or even increasing. For example, Mahony (1993) argued that a population around Kulnura (NSW) became locally extinct as a result of increased road traffic, as no individuals were detected in subsequent nocturnal road transects. No work was conducted away from the road and recent surveys have located individuals in the surrounding areas (F. L. Lemckert unpubl. data), suggesting that the species did not become extinct, rather that it may simply have stopped utilizing the road matrix.

\section{DISTURBANCE IMPACTS}

Fire

The primary impact that fire could have on this species is mortality, through overheating or dehydration (Lunney \& Barker 1986, Lemckert \& Brassil 2003). Using agar models, moisture loss during a hazard reduction burn was found to be unlikely to result in mortality for individuals buried at depths of $5 \mathrm{~cm}$ or greater (Penman et al. 2006c). As individuals occupy burrows at depths of 1 to $30 \mathrm{~cm}$, with an average depth of $10 \mathrm{~cm}$ (Lemckert \& Brassil 2003, Penman 2005), only a small proportion of the population may be directly affected by dehydration during a fire event - this presumes that individuals would not burrow deeper into the soil profile.

Table 1. Records of the giant burrowing frog Heleioporus australiacus from conservation reserves and lands managed for commercial forestry. NP: National Park, NR: Nature Reserve, SCA: State Conservation Area, SRA: State Recreation Area, SF: State Forest (New South Wales, NSW), FMA: Forest Management Area (Victoria)

\begin{tabular}{|c|c|c|}
\hline Northern NSW & Southern NSW & Victoria \\
\hline $\begin{array}{l}\text { Conservation Reserv } \\
\text { Wollemi NP } \\
\text { Yengo NP } \\
\text { Brisbane Water NP } \\
\text { Kurringhai NP } \\
\text { Marramarra NP } \\
\text { Jilliby SCA } \\
\text { Dharug NP } \\
\text { Popran NP } \\
\text { Blue Mountains NP } \\
\text { Garigal NP } \\
\text { Royal NP } \\
\text { Heathcote NP } \\
\text { Dharawal NP } \\
\text { Bargo SRA } \\
\text { Morton NP } \\
\text { Budderoo NP } \\
\text { Barren Grounds NR } \\
\text { Jervis Bay NP } \\
\text { Booderee NP }\end{array}$ & $\begin{array}{l}\text { Wadbilliga NP } \\
\text { Biamanga NP } \\
\text { Nadgee NR } \\
\text { South East Forest NP } \\
\text { Ben Boyd NP }\end{array}$ & $\begin{array}{l}\text { Snowy River NP } \\
\text { Coopracambra NP }\end{array}$ \\
\hline $\begin{array}{l}\text { Lands managed for } \\
\text { Olney SF } \\
\text { Putty SF } \\
\text { McPherson SF } \\
\text { Ourimbah SF } \\
\text { Strickland SF }\end{array}$ & $\begin{array}{l}\text { rcial forestry } \\
\text { Bodalla SF } \\
\text { Wandella SF } \\
\text { Dampier SF } \\
\text { Bermagui SF } \\
\text { Glenbog SF } \\
\text { Gnupa SF } \\
\text { Yurammie SF } \\
\text { Broadwater SF } \\
\text { Nullica SF } \\
\text { East Boyd SF } \\
\text { Timbillica SF } \\
\text { Yambulla SF } \\
\text { Bondi SF }\end{array}$ & $\begin{array}{l}\text { Boda FMA } \\
\text { Ben Cruachan FMA } \\
\text { Freestone FMA } \\
\text { Sandy Creek FMA } \\
\text { Marthavale FMA } \\
\text { Mount Alfred FMA } \\
\text { Sansfield FMA } \\
\text { Dead Horse FMA } \\
\text { Buldah FMA } \\
\text { West Colquhoun FMA } \\
\text { Boggy FMA } \\
\text { Gillingall FMA } \\
\text { Martins Creek FMA } \\
\text { Purgagoolah FMA } \\
\text { Coast Range FMA }\end{array}$ \\
\hline
\end{tabular}


Frequent anthropogenic fire is thought to simplify the structure and diversity of vegetation (e.g. Tasker \& Bradstock 2006). Similarly, the exclusion of fire from some vegetation communities is thought to result in changes in the vegetation structure and diversity (e.g. Penman et al. 2008). The indirect effects of changed fire regimes on the giant burrowing frog are not clear, as habitat requirements for this species are still not well understood.

\section{Logging}

During a logging operation, individual giant burrowing frogs are susceptible to being crushed by fallen trees and vehicle movements, a case of which was described by Lemckert et al. (1998). The extent of soil compaction is a function of both soil type and traffic levels (Grigal \& Bates 1997, Smith et al. 1997, Hutchings et al. 2002). The areas of highest traffic in a logging area, hence sites of compaction, are the tracks along which logs are transported (snig tracks) and the centralized log dumps. Individuals occupying these areas during a logging operation are likely to be crushed if they do not move during the initial disturbance (Lemckert et al. 1998, Penman et al. 2006d). The extent of soil compaction (and hence the potential for mortality) in areas where trees are felled without vehicle movements is not clear.

The post-logging environment may not provide suitable burrowing habitat for the giant burrowing frog. Logging operations reduce the vegetative cover across the ground; however, the proportion of woody debris will increase dramatically in the short term, thereby reducing burrowing opportunities. This may be overcome in part by the application of post-logging burns, which reduce the quantity of woody debris remaining within the coupe. Loss of vegetation from the site particularly in the understorey and shrub layers will reduce the shading effect for which the species appears to select (Penman 2005). This impact is likely to be relatively short, as early stages in the forest regeneration will provide shrub and understorey cover.

\section{CURRENT PRESCRIPTIONS}

Most of the current prescriptions for this species in land areas managed for forestry appear to be inappropriate. Existing prescriptions generally fail to provide protection to the key elements of the population, or appear to cover an unnecessarily large area. Another major limitation is that these prescriptions are only enforced if individuals are detected using standard- ized surveys; however, such surveys have to date been unsuccessful.

Stream-side buffer zones, as used for the northern populations and in Victoria, appear to be inappropriate for protecting populations of this species. Males are more likely to be found closer to the breeding site than females (Penman 2005). As a result, a disproportionate number of males relative to females will be protected by such prescriptions. This could result in a decline in the size of the female breeding population, which will reduce overall population size and genetic diversity. Multi-species studies have suggested that buffer zones of $300 \mathrm{~m}$ around breeding sites will protect a significant proportion of a number of species' populations (Semlitsch \& Bodie 2003). This would not, however, be practical in areas occupied by the giant burrowing frog, as most areas fall within $300 \mathrm{~m}$ of a potential breeding site. Therefore, to all intents and purposes, $300 \mathrm{~m}$ buffer zones would function as exclusion zones.

Exclusion zones are used in the southern populations within NSW (200 or $78 \mathrm{ha}$ ) and in non-breeding habitats in Victoria (50 ha). Individual burrowing frogs have average non-breeding activity areas of approximately 0.05 ha (Penman 2005). A 200 ha exclusion zone is therefore approximately 4000 times larger than an individual's activity area. In a radio-tracking study of a population over 3 successive seasons, no frogs were found to move outside the 200 ha exclusion zone established (Penman 2005). If exclusion zones continue to be enforced around every population that is detected, a 200 ha exclusion zone, then, is much larger than would be necessary to protect a population; a 50 ha exclusion zone is a more appropriate size for this species. In areas occupied by the giant burrowing frog, 50 ha would incorporate the majority of breeding and non-breeding sites used by a local population (Penman 2005).

\section{ALTERNATIVE PRESCRIPTIONS}

Two main scenarios exist that may represent the conservation status of this species:

(1) the species distribution is extremely patchy and the known sites reflect the main populations within this distribution; or

(2) the species is widespread within its distribution; however, due to difficulties in detecting the species current records do not reflect this.

Conservation management of this species should consider both scenarios and develop prescriptions that account for either possibility. The most suitable approach therefore appears to be reserving a number of known population areas throughout the species' range. This can encompass populations that are 
already reserved and, if necessary, populations not yet reserved if they are considered essential to the process. If these protection zones were to be established, pre-logging surveys would not be necessary and populations outside these areas would not be afforded additional protection. We take the Forests NSWSouth East Region, also known as the Eden Management Area (EMA), as a case study of how this could be implemented; this information is presented below.

Within these protection zones management actions should be restricted. Fire management practices (e.g. hazard reduction burns and the maintenance of important access trails) should be conducted. Hazard reduction burns reduce future fire risk by reducing fuel loads (e.g. Penman et al. 2007b). The direct impact of a hazard reduction burn on a population of Heleioporus australiacus is minimal, particularly when compared to the potential impact of an intense wildfire (Penman et al. 2006c). Hazard reduction burns could be carried out within a protection zone; however, following the precautionary principle, no entire protection zone should be burnt in any one season. The protection zone should be divided into a minimum of 3 fire management areas, which should be identified when the protection zone is designed. All logging should be excluded from these protection zones, as logging operations are likely to have negative impacts on the population, at least in the short term (Penman et al. 2006d).

Protection zones should be based on biologically meaningful areas and therefore may vary in size. These areas encompass a number of known breeding sites and non-breeding habitat areas. This may mean that additional surveys are required to adequately design the protection zones. It is anticipated that each protection zone will be approximately 400 to 600 ha. Boundaries of the protection zone should be clearly delineated by roads, mapped drainage lines or administrative boundaries, to ensure these areas can be readily identified by staff working in the field.

Implementing such a management approach requires subsequent monitoring of the populations, to determine not only the health of the population but the ensuing success of the whole operation. Attempting to obtain statistically valid results from monitoring pop- ulations of Heleioporus australiacus is likely to be extremely difficult. It is our opinion that monitoring breeding sites over successive seasons to determine the presence or absence of tadpoles is the most appropriate technique. Monitoring for the presence of tadpoles allows managers to assess whether an active breeding population persists in a given area. In contrast, nocturnal road transects and pitfall traps will generally only indicate whether an adult population persists in a given area.

Individuals move to the breeding site following heavy summer or autumn rains (Daly 1996, Penman 2005), and therefore some flexibility is required in the monitoring of populations. A minimum of 3 monitoring events should take place at each site following a heavy rainfall event. The first of these should be 1 mo after the rainfall event, with subsequent monitoring occurring at 3 to $4 \mathrm{wk}$ intervals. At each visit, surveyors should determine whether tadpoles of the giant burrowing frog are present, estimate the number of tad-

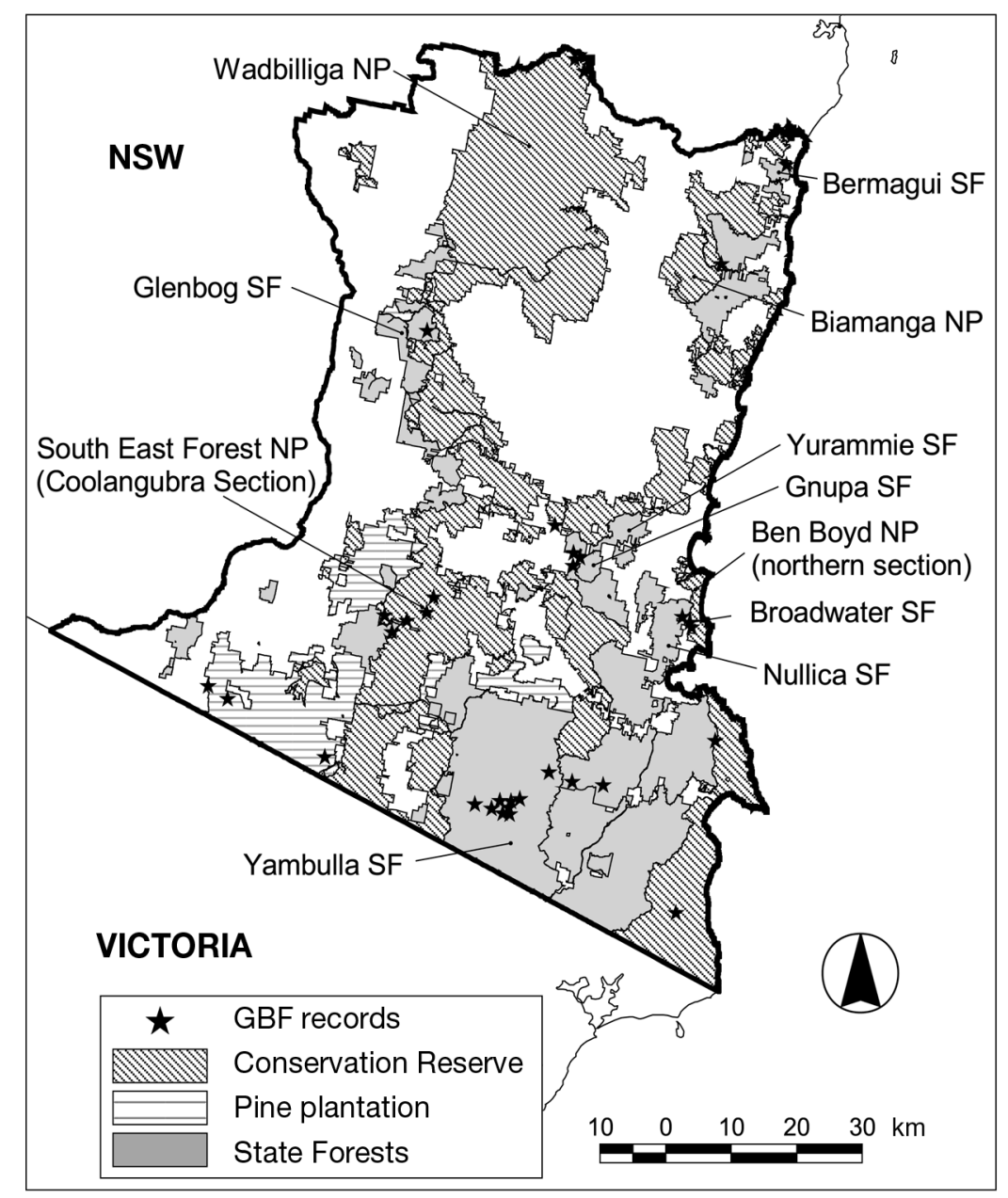

Fig. 2. Records of the giant burrowing frog (GBF) Heleioporus australiacus in the Eden Management Area (EMA), NSW. For abbreviations see Table 1 
poles in each pool on the stream and estimate an average size of each cohort in the pool.

\section{EDEN MANAGEMENT AREA: A CASE STUDY}

The EMA is located in the south-eastern corner of NSW (Fig. 2), covering an area of approximately 814249 ha or $8142.5 \mathrm{~km}^{2}$. Boundaries of the EMA are defined by the administrative boundaries of the SouthEast Region of Forests NSW (formerly State Forests of NSW). Within this area there are 248467 ha of conservation reserves, 214259 ha of native forest managed by Forests NSW for commercial forestry, 8886 ha of plantation forests and 35792 ha of native forest on privately owned land (Keith \& Bedward 1999). Heleioporus australiacus has been recorded from a total of 38 locations around the region (Fig. 2), although not all of these records have been verified. A summary of the observations is presented in Table 2 . These sites $(n=38)$ are scattered throughout the various forest areas within the region, with 11 falling in conservation reserves, 23 within land managed for commercial forestry, 3 from native forest which has subsequently been converted to plantations and 1 from private land. This bias does not necessarily reflect habitat selectivity, but rather survey effort within the region.

To develop the proposed management approach it is necessary to understand the distribution of potential habitat. Several attempts have been made to predict the habitat for Heleioporus australiacus within this region using spatial models (NSW National Parks and Wildlife Service 1998, Penman et al. 2005a, 2007a). These models have not always provided valuable information to managers, as they have either failed to predict known populations, thus the veracity of the model is questionable (NSW National Parks and Wildlife Service 1998) or predict most if not all of the forest environments and thereby provide no useful guidance for targeted surveys (Penman et al. 2005a). Recent modeling attempts have consistently predicted the majority of the Wadbiligia Nature Reserve (NR) and the southern end of Nullica State

Table 2. Summary of observations in the Eden Management Area (EMA)

\begin{tabular}{|lcc|}
\hline Observation type & Reliability & No. of sites \\
\hline Museum specimen & Very high & 10 \\
Individual captured & High to very high & 22 \\
Heard call & Low & 1 \\
Anecdotal evidence & Variable & 4 \\
Burnt body & Low & 1 \\
Total & & 38 \\
\hline
\end{tabular}

Forest (SF) as unsuitable habitat for $H$. australiacus, probably due to the steep and dry nature of these areas. Outside this area, suitable habitat for the species appears to exist throughout the naturally vegetated areas of the EMA.

The proposed management approach identifies key populations for protection within the EMA. We suggest that a minimum of 5 population areas be protected that have significant spatial separation and incorporate the range of geographic and ecological conditions in which the species is found. Four areas within the EMA exist, from which a large number of records have been derived. These are Nullica/Broadwater SF (hereafter the Broadwater population), the Coolangubra section of the South-East Forests National Park (NP) (hereafter the Coolangubra population), Yambulla SF (hereafter the Yambulla population) and to a lesser extent the Gnupa/Yurammie SF (hereafter the Gnupa population) (Fig. 2). A number of individuals have been seen in all of these areas, but successful breeding has only been confirmed for the Broadwater population. Before any additional populations are identified for protection, additional survey work is necessary to determine the status of the populations at these sites. Options for this include the record of the species in Glenbog SF or one of the populations in the north-east of the region (Bermagui SF or Biamanga NP). All of these populations are geographically separated from the main known populations.

Protection around key populations should not necessarily be based on a single sized area, rather one that is biologically meaningful for the species. Ideally, a protection zone will incorporate a number of breeding sites, as well as a large number of the known records for that population. These are not known for many populations in the EMA; therefore additional survey work should be conducted before protection zones can be designed to meet these criteria. In the following we outline an initial design for the Broadwater population, which has been studied intensively.

The Broadwater population lies on the boundary of Broadwater SF, Nullica SF and the northern section of East Boyd NP (Fig. 2). This area has been intensively surveyed with tadpole surveys, pitfall traps, nocturnal road transects, auditory surveys and a radio-tracking study. Breeding sites, non-breeding records and the boundary of the proposed protection zone are depicted in Fig. 3. The protection zone (630 ha: 435 ha managed by Forests NSW, 195 ha by the National Parks and Wildlife Service, NPWS) incorporates all known breeding sites and the majority of the non-breeding records for the species. It is not expected that the level of survey effort that has been placed into the Broadwater population would be placed into the other population areas. Appropriately timed tadpole surveys should 




Fig. 3. Broadwater giant burrowing frog Heleioporus australiacus population, showing breeding sites, non-breeding sites (capture points) and proposed protection zone
(3) a study examining the direct impact of hazard reduction burns on individuals of the giant burrowing frog using surrogate measures; and

(4) a study examining the direct impact of forestry operations on individuals of the giant burrowing frog using surrogate measures.

\section{CONCLUSION}

The giant burrowing frog is an extremely difficult species to detect, even in areas where it is known to occur. Commercial forestry is likely to impact negatively upon populations in the short term; however, the severity of this impact remains uncertain. Additionally, we have little knowledge of longerterm impacts, even though most records in the south-east of NSW and many in the north originate from previously disturbed sites. Existing management prescriptions are inappropriate for the species for 2 reasons: firstly, they require the detection of individuals and secondly, the areas do not provide sufficient protection to the population or they are unnecessarily large. Recent information indicates that successful management of this species is most likely to be achieved by focusing on protecting key populations across a region, and monitoring the health of these populations through time. allow for similar zones to be easily developed in the other population areas.

\section{FUTURE RESEARCH}

Any research on this species is liable to be difficult (at least resource- and time-consuming) and it is thus important that the funds and effort be placed into appropriate activities. We suggest that the following questions are most relevant to the conservation biology of this species at this point in time:

(1) an assessment of tadpole surveys as a means of detecting the species;

(2) pending the success of (1), a study examining the distribution of the species on a regional level in all potential habitat areas;
Acknowledgements. This work brings together the results of a study funded by an Australian Postgraduate Industry Award to the University of Newcastle supported by State Forests of NSW and NSW National Parks and Wildlife Service. Discussions with Chris Slade, Adam Fawcett, Steve Dodds, Martin Linehan, Rod Pietsch and Mike Saxon have aided the development of this paper.

\section{LITERATURE CITED}

Anstis M (2002) Tadpoles of south-eastern Australia - a guide with keys. Reed New Holland, Sydney

Daly G (1996) Observations of the eastern owl frog Heleioporus australiacus (Anura: Myobatrachidae) in southern New South Wales. Herpetofauna 26:33-42

Gillespie GR (1990) Distribution, habitat and conservation status of the giant burrowing frog (Heleioporus australiacus) in Victoria. Vic Nat 5/6:144-153

Gillespie G, Hines H (1999) Status of temperate riverine frogs in south-eastern Australia. In: Campbell A (ed) Declines 
and disappearances of Australian frogs. Environment Australia, Canberra, p 109-130

Grigal DF, Bates PC (1997) Assessing impacts of forest harvesting - the Minnesota experience. Biomass Bioenerg 13:213-222

Hutchings TR, Moffat AJ, French CJ (2002) Soil compaction under timber harvesting machinery: a preliminary report on the role of brash mats in its prevention. Soil Use Manag 18:34-38

Kavanagh RP, Webb GA (1998) Effects of variable-intensity logging on mammals reptiles and amphibians at Waratah Creek, southeastern New South Wales. Pac Conserv Biol 4:326-347

Keith DA, Bedward M (1999) Native vegetation of the South East Forests region, Eden, New South Wales. Cunninghamia 6:1-218

Lemckert FL, Brassil TD (2003) Movements and habitat use of the endangered giant burrowing frog, Heleioporus australiacus, and its conservation in forestry areas. AmphibReptilia 24:207-211

Lemckert F, Brassil T, McCray K (1998) Recent records of the giant burrowing frog (Heleioporus australiacus) from the far south coast of NSW. Herpetofauna 28:32-39

Littlejohn M, Martin AA (1967) The rediscovery of Heleioporus australiacus in eastern Victoria. Proc R Soc Vic 80: 31-35

Lunney D, Barker J (1986) Survey of reptiles and amphibians of the coastal forests near Bega, NSW. Aust Zool 22:1-9

Lunney D, Curtin AL, Ayers D, Cogger HG and others (2000) The threatened and non-threatened native vertebrate fauna of New South Wales: status and ecological attributes. National Parks and Wildlife Service (NPWS), Sydney

MacKenzie DI, Nichols JD, Hines JE, Knutson MG, Franklin AB (2003) Estimating site occupancy, colonization, and local extinction when a species is detected imperfectly. Ecology 84:2200-2207

Mahony MJ (1993) The status of frogs in the Watagan Mountains area of the Central Coast of New South Wales. In: Lunney D, Ayers D (eds) Herpetology in Australia: a diverse discipline. Royal Zoological Society of NSW, Mosman, p 257-264

Martin A (1997) Gorillas in the garden: zoology and zoos. Surrey Beatty \& Sons, Sydney

Mazzer T (1994) The giant burrowing frog (Heleioporus australiacus). Flora and Fauna Guarantee Action Statement No. 61. Department of Conservation and Natural Resources, Victoria

NSW National Parks and Wildlife Service (1998) Eden fauna modelling - a report undertaken for the NSW CRA/RFA Steering Committee. NSW NPWS, Queanbeyan

Penman TD (2005) Applied conservation biology of a threatened forest dependent frog, Heleioporus australiacus. PhD Thesis, University of Newcastle

Penman T, Lemckert F, Mahony M (2004) Two hundred and ten years looking for the giant burrowing frog. Aust Zool 32:597-604

Editorial responsibility: Luca Luiselli, Rome, Italy
Penman TD, Mahony MJ, Towerton AL, Lemckert FL (2005a) Bioclimatic analysis of disjunct populations of the giant burrowing frog, Heleioporus australiacus. J Biogeogr 32: 397-405

Penman T, Lemckert F, Slade C, Mahony M (2005b) Nonbreeding habitat requirements of the giant burrowing frog, Heleioporus australiacus (Anura: Myobatrachidae) in south-eastern Australia. Aust Zool 33:251-257

> Penman TD, Lemckert FL, Mahony MJ (2006a) Meteorological effects on the activity of the giant burrowing frog (Heleioporus australiacus) in south-eastern Australia. Aust Wildl Res 33:35-40

$>$ Penman TD, Lemckert FL, Mahony MJ (2006b) A cost-benefit analysis of automated call recorders. Appl Herpetol 2: 389-400

Penman TD, Lemckert FL, Mahony MJ (2006c) A preliminary investigation into the potential impacts of fire on a forest dependent burrowing frog species. Pac Conserv Biol 12: 78-83

> Penman TD, Mahony MJ, Lemckert FL (2006d) Soil disturbance in integrated logging operations and the potential impact on a fossorial Australian frog. App Herpetol 2: 415-424

Penman TD, Mahony MJ, Towerton AL, Lemckert FL (2007a) Spatial models of giant burrowing frog distributions. Endang Species Res 3:115-124

Penman TD, Kavanagh RP, Binns DL, Melick DR (2007b) Patchiness of prescribed burns in dry sclerophyll eucalypt forests in south-eastern Australia. For Ecol Manag 252: $24-32$

> Penman TD, Binns DL, Shiels RJ, Allen RM, Kavanagh RP (2008) Changes in understorey plant species richness following logging and prescribed burning in shrubby dry sclerophyll forests of south-eastern Australia. Aust Ecol 33:197-210

Semlitsch RD, Bodie JR (2003) Biological criteria for buffer zones around wetland and riparian habitats for amphibians and reptiles. Conserv Biol 17:1219-1228

Smith CW, Johnston MA, Lorentz S (1997) The effect of soil compaction and soil physical properties on the mechanical resistance of South African forestry soils. Geoderma 78: 93-111

Strahler AN (1952) Dynamic basis of geomorphology. Geol Soc Am Bull 63:923-938

> Tasker EM, Bradstock RA (2006) Influence of cattle grazing practices on forest understorey structure in north-eastern New South Wales. Aust Ecol 31:490-502

Tyler M (1997) The action plan for Australian frogs. Wildlife Australia, Canberra

Tyre AJ, Tenhumberg B, Field SA, Niejalke D, Parris K, Possingham HP (2003) Improving precision and reducing bias in biological surveys: estimating false-negative error rates. Ecol Appl 13:1790-1801

Webb GA (1987) A note on the distribution and diet of the giant burrowing frog, Heleioporus australiacus (Shaw and Nodder 1795) (Anura: Myobatrachidae). Herpetofauna 17: $20-21$

Wintle BA, McCarthy MA, Parris KM, Burgman MA (2004) Precision and bias of methods for estimating point survey detection probabilities. Ecol Appl 14:703-712

Submitted: March 15, 2008; Accepted: May 30, 2008

Proofs received from author(s): August 8, 2008 